\title{
ANNOUNCEMENT
}

\section{SYMPOSIUM ON INSECT-PLANT RELATIONSHIPS}

The 8th International Symposium on Insectplant Relationships will be held on 9-13 March 1992 at Wageningen, The Netherlands.

Topics to be discussed will include:

\section{Hostplant Selection \\ Insect-plant Communities \\ Plant Defenses \\ Multitrophic Interactions \\ Genetics and Evolution \\ Plant Resistance}

In addition to invited papers the programme will include submitted oral and poster presentations. Proceedings of the meeting will be published before the end of the year.
First circular and organizational matters:

\author{
IAC, Section OCC \\ P. O. Box 88 \\ $6700 \mathrm{AB}$ Wageningen, The Netherlands \\ Telephone + 31-8370-90111, \\ Fax + 31-8370-18552
}

Further inquiries:
Dr. J. H. Visser
Research Institute for Plant Protection P. O. Box 9060 $6700 \mathrm{GW}$ Wageningen, The Netherlands Telephone +31-8370-76002,
Fax +31-8370-10113 